\title{
Five-year prospective evaluation of thyroid function in girls with subclinical mild hypothyroidism of different etiology
}

\author{
Malgorzata Wasniewska, Tommaso Aversa, Mariacarolina Salerno', \\ Andrea Corrias' ${ }^{2}$, Maria Francesca Messina, Alessandro Mussa ${ }^{2}$, Donatella Capalbo', \\ Filippo De Luca and Mariella Valenzise
}

Department of Pediatric, Gynecological, Microbiological and Biomedical Sciences, University of Messina, Via Consolare Valeria, 98125 Messina, Italy, ${ }^{1}$ Pediatric Endocrinology Unit, Department of Translational Medical Sciences, University 'Federico II', Naples, Italy and ${ }^{2}$ Department of Pediatrics, University of Turin, Turin, Italy
Correspondence should be addressed to F De Luca

Email

filippo.deluca@unime.it

\begin{abstract}
Aim: To follow-up for 5 years thyroid status evolution in 127 girls with mild (TSH 5-10 mU/l) subclinical hypothyroidism (SH) of different etiologies.

Patients: The population was divided into two age-matched groups of 42 and 85 girls with either idiopathic (group A) or Hashimoto's thyroiditis (HT)-related SH (group B). Group B was in turn divided into three subgroups, according to whether SH was either isolated or associated with Turner syndrome (TS) or Down syndrome (DS).

Results: At the end of follow-up the rate of girls who became euthyroid was higher in group A (61.9\% vs $10.6 \%)$, whereas the rates of patients who remained SH (55.3\% vs $26.2 \%)$, became overtly hypothyroid $(30.6 \%$ vs $11.9 \%)$ or required levothyroxine ( $\left(-\mathrm{T}_{4}\right)$ therapy ( $63.5 \%$ vs $23.8 \%$ ) were higher in group B. Among the girls of group B, the risk of remaining $\mathrm{SH}$ or developing overt hypothyroidism was higher in the subgroups with TS or DS than in those with isolated HT.

Conclusions: Long-term prognosis of mild and idiopathic $\mathrm{SH}$ is frequently benign, even though a $\mathrm{L}^{-\mathrm{T}_{4}}$ treatment may be needed throughout follow-up in almost a quarter of cases; long-term prognosis is different in the girls with either idiopathic or HT-related SH; and the association with either TS or DS impairs the outcome of HT-related SH.
\end{abstract}

\section{Introduction}

Subclinical hypothyroidism (SH) is a biochemical condition characterized by serum thyrotropin (TSH) concentrations above the upper limit of the reference range and serum free thyroxine $\left(\mathrm{FT}_{4}\right)$ levels within the reference range (1). In pediatric age, $\mathrm{SH}$ is detected with increasing frequency, as thyroid function tests are routinely performed in children with very different clinical problems $(2,3)$. SH may be possibly caused by the same thyroid disorders that result in overt thyroid function impairment, in particular, Hashimoto's thyroiditis (HT) (4). In many cases, however, no definite etiology can be found (idiopathic SH).
The main clinical problem in the patients with $\mathrm{SH}$ is whether they should be treated or not, a problem that is still controversial due to the lack, even in adulthood, of randomized trials revealing significant benefits of levothyroxine ( $\left.\mathrm{L}_{-} \mathrm{T}_{4}\right)$ treatment on hypothyroid symptoms, life quality, serum lipid levels, and/or heart function (5).

In childhood, this is an even more controversial issue $(6,7,8,9,10)$ and the only available study comparing the effects of $\mathrm{L}-\mathrm{T}_{4}$ treatment vs no therapy in idiopathic $\mathrm{SH}$ suggests that therapy is unable to modify post-therapy outcome of hyperthyrotropinemia and to prevent the risks

Published by Bioscientifica Ltd. 
of a subsequent TSH increase after treatment withdrawal (11). In the children with HT-related mild SH, it has been just recently reported that the evolution of thyroid function tests seems to be frequently characterized by a deterioration over time, whereas such risk is very low in the children with idiopathic SH (12). However, the available prospective studies on the natural history and prognosis of SH in children are very few and based on 2-3 years follow-up investigations $(12,13,14,15,16)$, which hampers the ability of drawing firm conclusions about the relevance of those findings.

In the present study, we have prospectively investigated the evolution of thyroid hormonal status, throughout a 5-year period, in a selected population consisting of only girls with either idiopathic or HT-related mild SH. In a limited number of cases, HT was associated with either Turner syndrome (TS) or Down syndrome (DS), i.e., two chromosomopathies that are known to be linked with an increased risk of autoimmune diseases $(17,18,19,20,21$, $22,23,24,25)$ and especially thyroid diseases $(26,27,28$, $29,30,31)$.

The aims of our study were to establish, through a prolonged follow-up, whether long-term thyroid status prognosis may differ in the girls with either idiopathic or HT-related mild $\mathrm{SH}$ and whether the association with either TS or DS may modify the outcome of HT-related SH.

\section{Patients and methods}

\section{Study population}

The study population consisted, overall, of 127 girls aged between 2.5 and 18.0 years at the time of $\mathrm{SH}$ diagnosis (median 9.7 years), who were identified in our clinics, during the period 2000-2008, as having a mild and either idiopathic or HT-related $\mathrm{SH}$ and fulfilled the following inclusion criteria: age $\leq 18.0$ years at the time of $\mathrm{SH}$ diagnosis; TSH serum levels ranging between 5 and $10 \mathrm{mU} / \mathrm{l}$; and no concomitant chronic treatment with pharmacological agents that might interfere with $\mathrm{SH}$ progression, such as antiepileptics, glucocorticoids, or iodinated drugs.

The entire series was divided into two groups, according to whether $\mathrm{SH}$ in the different cases was idiopathic (group A) or HT-related (group B). Patients of group A fulfilled the following criteria: negativity for both thyroglobulin and thyroid peroxidase serum autoantibodies (TGAbs and TPOAbs respectively) and no thyroid enlargement and no hypoechogenic gland pattern at ultrasonography. Patients of group $B$ fulfilled the following criteria for diagnosis of HT: positivity for serum TGAbs or TPOAbs and a hypoechogenic thyroid pattern, consistent with autoimmune thyroid disease.

In both groups the patients were in good clinical status and clinically euthyroid at the time of recruitment. All of them had been referred to our pediatric endocrine centers by their pediatricians, due to the incidental finding of high TSH levels at their annual check-up, based on a diagnostic protocol that also included TSH measurement.

Group A consisted of 42 girls who were younger than 15 years at recruitment. Of these, 27 were prepubertal and 15 pubertal. Group B consisted of 85 girls, who were not older than 18 years at recruitment. Of these, 57 were prepubertal and 28 pubertal (Table 1).

Table 1 Ages (years) and prevalences (\%) of pubertal patients, TSH (mIU/l), $\mathrm{FT}_{4}$ (pmol/l), thyroid peroxidase and thyroglobulin autoantibody (TPOAbs and TgAbs) serum levels (mIU/l) at the start of follow-up in the two groups with either idiopathic subclinical hypothyroidism (SH; group A) or Hashimoto's thyroiditis (HT)-related SH and in three subgroups of patients with HT-related SH.

\begin{tabular}{l}
\hline \\
\hline Group A $(n=42)$ \\
Group B $(n=85)$ \\
$P$ \\
Subgroup B1 ${ }^{\mathrm{a}}(n=22)$ \\
Subgroup B2 ${ }^{\mathrm{b}}(n=21)$ \\
Subgroup B3 $(n=42)$ \\
$P$ B1 vs B2 \\
$P$ B1 vs B3 \\
$P$ B2 vs B3
\end{tabular}

\begin{tabular}{c} 
Age \\
\hline $7.4(2.5-14.0)$ \\
$9.0(2.5-18)$ \\
0.2000 \\
$10.5(4.0-15.9)$ \\
$13.3(6.3-18.0)$ \\
$4.5(2.5-18.0)$ \\
0.0070 \\
0.0004 \\
0.0001
\end{tabular}

\begin{tabular}{l} 
Pubertal \\
patients \\
\hline 35.7 \\
32.9 \\
0.7550 \\
50.0 \\
42.9 \\
19.0 \\
0.6400 \\
0.0100 \\
0.0450 \\
\hline
\end{tabular}

\begin{tabular}{c}
\hline TSH \\
\hline $6.0(5.0-9.9)$ \\
$6.4(5.0-9.9)$ \\
0.0420 \\
$5.6(5.0-7.8)$ \\
$7.3(5.0-9.4)$ \\
$7.0(5.0-9.9)$ \\
0.0008 \\
0.0020 \\
0.7970
\end{tabular}

\begin{tabular}{c}
\hline $\mathbf{F T}_{\mathbf{4}}$ \\
\hline $14.3 \pm 3.4$ \\
$13.3 \pm 3.0$ \\
0.1160 \\
$14.3 \pm 3.4$ \\
$13.9 \pm 2.5$ \\
$12.1 \pm 3.5$ \\
0.6440 \\
0.0240 \\
0.0530
\end{tabular}

\begin{tabular}{c}
\hline TPOAbs \\
\hline- \\
$100(34-6400)$ \\
- \\
$305.5(40-2042)$ \\
$347.0(40-6400)$ \\
$66.4(34-2400)$ \\
0.0420 \\
0.4420 \\
0.0030
\end{tabular}

\begin{tabular}{c}
\hline TGAbs \\
\hline- \\
$96(28-2500)$ \\
- \\
$172.5(35-2002)$ \\
$100.0(35-2500)$ \\
$50(29-1926)$ \\
0.5780 \\
0.0007 \\
0.0450
\end{tabular}

a No association with either Turner or Down syndrome.

${ }^{\mathrm{b}}$ Association with Turner syndrome.

${ }^{\mathrm{c} A s s o c i a t i o n ~ w i t h ~ D o w n ~ s y n d r o m e . ~}$ 
Patients of group B were in their turn divided into three subgroups, according to whether HT-related SH was either isolated (subgroup B1), associated with TS (subgroup B2), or DS (subgroup B3). These subgroups consisted, respectively, of 22, 21, and 42 girls.

Median ages (and ranges) at the start of follow-up and prevalences of the girls who had entered puberty at that time, in the different groups and subgroups, are detailed in Table 1.

\section{Study design}

All of the girls who were diagnosed in our clinics, during the period 2000-2008, as having a mild and either idiopathic or HT-related SH and fulfilled the above reported inclusion criteria were consecutively recruited for this prospective study.

From the time of recruitment all of them were followed-up as outpatients every 12 months for a preestablished period of 5 years and only those who completed the entire follow-up period were considered for this study.

At each examination $\mathrm{TSH}, \mathrm{FT}_{4}$, TPOAb, and TGAb serum levels were investigated. In the patients who exhibited, at the annual investigations, a further increase in TSH levels to $>10 \mathrm{mIU} / \mathrm{l}$ and/or a pathological decrease of $\mathrm{FT}_{4}$ levels to $<10.3 \mathrm{pmol} / \mathrm{l}, \mathrm{L}-\mathrm{T}_{4}$ treatment was begun immediately, according to our guidelines (4) and other recommendations $(32,33)$. In the patients who, during follow-up, exhibited a dramatic fall in TSH serum levels to $<0.3 \mathrm{mIU} / \mathrm{l}$ and/or a concomitant increase of $\mathrm{FT}_{4}$ to $>24.4 \mathrm{pmol} / \mathrm{l}$, methimazole treatment was begun immediately.

With regard to thyroid function at the end of the 5-year observation period, patients of both groups were evaluated according to $\mathrm{FT}_{4}$ and TSH serum levels and classified into the following biochemical patterns: euthyroidism (both TSH and $\mathrm{FT}_{4}$ within normal limits); $\mathrm{SH}$ (normal $\mathrm{FT}_{4}$, as opposed to elevated TSH); overt hypothyroidism (elevated TSH with low $\mathrm{FT}_{4}$ ); and hyperthyroidism (suppressed TSH, as opposed to either normal or elevated $\mathrm{FT}_{4}$ ).

The prevalence rates of the patients who, in the two groups, either normalized or maintained TSH within the initial limits, exhibited an overt hypothyroidism biochemical picture at the end of follow-up or required $\mathrm{L}-\mathrm{T}_{4}$ therapy during the 5-year follow-up period were compared between them. The same comparisons were performed, in the context of group B patients, among those belonging to the subgroups B1, B2, and B3.
The girls who were under $\mathrm{L}-\mathrm{T}_{4}$ therapy at the end of 5-year follow-up were analyzed 6 weeks after treatment withdrawal. Those who were under methimazole treatment at the end of observation period were considered as patients who shifted over time from HT to Graves' disease (GD), provided that TSH receptor autoantibodies (TRABs) were positive.

\section{Methods}

Serum levels of TSH (normal range $0.3-4.5 \mathrm{mIU} / \mathrm{l}$ ) and $\mathrm{FT}_{4}$ (normal range 10.3-24.4 pmol/l) were measured by RIA methods. TPOAbs (reference range $0-20 \mathrm{IU} / \mathrm{ml}$ ) and TGAbs (reference range $0-30 \mathrm{IU} / \mathrm{ml}$ ) were measured by chemiluminescent immunometric assays (34).

TRAB serum levels were measured by a second generation radioreceptor assay using the human recombinant TSH receptor only in the patients who, during follow-up, developed a hyperthyroid biochemical picture and underwent methimazole therapy. According to this method, values above $1.5 \mathrm{IU} / \mathrm{ml}$ are considered as positive (35).

\section{Statistical analysis}

Results are expressed as mean \pm s.D. or median and range values, as appropriate. Comparisons between groups were performed by Student's unpaired and paired $t$-test (normally distributed data) or Mann-Whitney and Wilcoxon test (non-normally distributed data), as appropriate. Frequency rates were compared by the $\chi^{2}$ test. Correlations between quantitative variables were assessed using Pearson's correlation analysis. The level of significance was set at 0.05 for all of the statistical analyses. The study design was approved by the ethical committees of the hospitals participating in our study and the children' parents gave informed consent. Appropriate consent was also obtained earlier from the study group for thyroid diseases of the Italian Society for Pediatric Endocrinology and Diabetology.

\section{Results}

\section{Main data at the start of follow-up}

Median age at follow-up onset was not significantly different in the girls of group A than in those of group B (Table 1). Even though expressed as mean \pm s.D., patients' age at entry was similar in these two groups $(7.5 \pm 3.8$ years vs $8.9 \pm 4.9$ years, $P=0.200$ ). Furthermore, the prevalence rates of patients who had entered puberty at follow-up initiation did not significantly differ in these two groups. 
Among the girls of group B, the oldest ones belonged to subgroup B2, while the youngest ones belonged to subgroup B3. Consequently, the prevalence of girls who had entered puberty at the time of $\mathrm{SH}$ diagnosis was significantly lower in subgroup B3 than in the other two subgroups.

TSH values were initially slightly higher in group B than in group $\mathrm{A}$, whereas no differences were detected between these groups in terms of $\mathrm{FT}_{4}$ values.

In the context of girls with HT-related $\mathrm{SH}$, those with DS (subgroup B3) exhibited both higher TSH and lower $\mathrm{FT}_{4}$ values with respect to those of subgroup B1, whereas the girls with TS (subgroup B2) exhibited higher TSH but very similar $\mathrm{FT}_{4}$ levels when compared with subgroup B1 patients. Both $\mathrm{TSH}$ and $\mathrm{FT}_{4}$ values were not different in subgroups B2 and B3.

The lowest autoantibody serum levels were initially found in the subgroup of girls with DS, whereas no differences were detected between subgroups B1 and B2.

\section{Main data at the end of follow-up}

Median age at the end of follow-up was very similar in the girls of groups A and B and no significant differences between these cohorts were detected even though age was expressed as mean \pm s.D. $(12.3 \pm 4$.0 years vs $13.8 \pm 4.9$ years, $P=0.0941$; Table 2). Furthermore, the prevalence rates of patients who had entered puberty at the time of study withdrawal did not significantly differ in these groups.

Among the girls of group B, the oldest ones belonged to subgroup B2, whereas the youngest ones belonged to subgroup B3. Consequently, the prevalence of girls who had entered puberty at the end of follow-up period was significantly lower in subgroup B3 than in the other two subgroups.

During follow-up median TSH serum levels significantly decreased in the patients of group A, while they significantly increased in group B girls. Therefore, at the end of follow-up, median TSH values became significantly higher in group B patients than in those of group A. By contrast, during the same observation period, mean $\mathrm{FT}_{4}$ serum levels significantly decreased in group B girls, whereas they remained unchanged in those of group A. Nevertheless, mean $\mathrm{FT}_{4}$ levels, at the end of follow-up, did not significantly differ in these two groups.

In the context of patients with HT-related $\mathrm{SH}$, during follow-up, those with TS (subgroup B2) as well as the girls with no chromosomopathies (subgroup B1) exhibited both a significant increase of TSH values and a significant decrease of $\mathrm{FT}_{4}$ values. By contrast, during the follow-up period, the girls of subgroup B3 maintained substantially unchanged baseline TSH and $\mathrm{FT}_{4}$ serum levels.

As a consequence of these time-related changes, at the end of follow-up, the girls of subgroup B2 showed the highest $\mathrm{TSH}$ values and the lowest $\mathrm{FT}_{4}$ values, with respect to the patients of the other two subgroups. By contrast, at the end of follow-up, the girls with DS exhibited TSH and $\mathrm{FT}_{4}$ serum levels that were not significantly different than those detected in subgroup B1 patients.

\section{Thyroid function patterns at the end of 5-year follow-up}

At the end of follow-up, the majority of girls with idiopathic SH (26/42) became biochemically euthyroid,

Table 2 Age (years) and prevalence (\%) of pubertal patients and TSH (mIU/l) and $\mathrm{FT}_{4}(\mathrm{pmol} / \mathrm{l})$ serum levels at the end of follow-up in the two groups with either idiopathic subclinical hypothyroidism (SH; group A) or Hashimoto's thyroiditis (HT)-related SH and in three subgroups of patients with HT-related SH.

\begin{tabular}{|c|c|c|}
\hline & Age & Pubertal patients \\
\hline Group A $(n=42)$ & $12.1(7.5-19.0)$ & 66.7 \\
\hline Group B $(n=85)$ & $14.4(7.5-23.0)$ & 71.8 \\
\hline$P$ & 0.0941 & 0.5550 \\
\hline Subgroup $\mathrm{B}^{\mathrm{a}}(n=22)$ & $15.7(9.0-20.9)$ & 95.5 \\
\hline Subgroup $\mathrm{B}^{\mathrm{b}}(n=21)$ & $18.3(11.3-23.0)$ & 95.2 \\
\hline Subgroup $\mathrm{B}^{\mathrm{C}}(n=42)$ & $9.0(7.5-23.0)$ & 47.6 \\
\hline$P$ B1 vs B2 & 0.0092 & 0.9731 \\
\hline$P$ B1 vs B3 & 0.0004 & 0.0002 \\
\hline$P$ B2 vs B3 & 0.0001 & 0.0002 \\
\hline
\end{tabular}

\begin{tabular}{c}
\hline TSH \\
\hline $2.4(1.2-13.8)$ \\
$7.6(1.1-15.0)$ \\
0.0023 \\
$8.0(1.1-14.2)$ \\
$12.7(6.9-15.0)$ \\
$7.1(2.2-14.2)$ \\
0.0176 \\
0.2279 \\
0.0121
\end{tabular}

\begin{tabular}{c}
\hline $\boldsymbol{P} *$ \\
\hline 0.0196 \\
0.0005 \\
0.0390 \\
0.0017 \\
0.5790 \\
\end{tabular}

\begin{tabular}{cccc}
\hline $\mathbf{F T}_{\mathbf{4}}$ & & $\boldsymbol{P}^{*}$ \\
\cline { 1 - 1 } $14.5 \pm 2.3$ & & 0.9284 \\
$12.1 \pm 2.7$ & & 0.0064 \\
0.0821 & & \\
$13.1 \pm 3.9$ & & 0.0017 \\
$9.0 \pm 2.5$ & & 0.0120 \\
$12.5 \pm 1.4$ & & 0.9585 \\
0.0076 & & \\
0.3141 & & \\
0.0092 &
\end{tabular}

*Vs the corresponding levels measured at the start of follow-up.

${ }^{a}$ No association with either Turner or Down syndrome.

${ }^{b}$ Association with Turner syndrome.

cAssociation with Down syndrome.

www.eje-online.org 
whereas such an evolutive pattern was observed in a very low number of girls with HT-related SH (9/85) (Table 3).

Among the 16 patients of group A who did not become over time biochemically euthyroid, 10 (62.5\%) required $\mathrm{L}-\mathrm{T}_{4}$ treatment during follow-up. Over time, five of them had developed an overt hypothyroidism and the remaining five had increased their TSH values to $>10 \mathrm{mU} / \mathrm{l}$.

In the context of group B, most girls maintained, over time, a condition of $\mathrm{SH}$ or deteriorated their thyroid function picture to overt hypothyroidism. The prevalence of patients who needed $\mathrm{L}_{\mathrm{T}} \mathrm{T}_{4}$ therapy during follow-up was, therefore, significantly higher in the patients of group B than in those of group A.

In group $\mathrm{B}$, the poorest scores in terms of TSH normalization during follow-up were observed in both the subgroups with chromosomopathies. Nevertheless, while most girls with TS worsened their initial thyroid function pattern from $\mathrm{SH}$ to overt hypothyroidism over time, the majority of those with DS remained SH.

If subgroup B1 girls were compared with those of group A, the risk of developing an overt hypothyroidism over time was significantly higher $(45.4 \%$ vs $11.9 \%$, $P=0.003$ ). Furthermore, the percentage of subgroup B1 girls who required $\mathrm{L}-\mathrm{T}_{4}$ therapy during follow-up was significantly higher $(63.6 \%$ vs $23.8 \%, P=0.002)$.

A shifting from HT to GD (with increased $\mathrm{FT}_{4}$, suppressed TSH and positive TRABs) was recorded during follow-up in 3/85 girls of group B (but in none of group A). All of these girls belonged to the subgroup B3.

\section{Discussion}

To the best of our knowledge, this is the first prospective study aiming to compare the outcome of thyroid function tests, after a 5-year follow-up, in two sex- and age-matched pediatric populations with either idiopathic or HT-related mild SH.

The first consideration, which emerges from the analysis of the results of our longitudinal study, is that the natural history of idiopathic SH in pediatric age seems to be characterized by a benign long-term evolution. In fact, the majority of these patients (61.9\%) spontaneously normalized over time their TSH values, and only a small minority (11.9\%) became overtly hypothyroid. Nevertheless, it has to be pointed out that almost a quarter of group A girls required $\mathrm{L}-\mathrm{T}_{4}$ treatment during the observation period, which underlines the importance of a biochemical follow-up, even in the children with idiopathic and mild SH $(33,36)$. According to the recent guidelines of the European Thyroid Association, in these children monitoring can be performed every 12 months due to the low risk of progression (33).

Furthermore, the results of the present study confirm, on the basis of a more prolonged prospective evaluation, the recent inference that underlying HT negatively affects the natural course of SH in children, irrespective of other concomitant risk factors (12). In fact, when compared with group A girls, those belonging to group B exhibited both decreased probabilities of TSH normalization and an increased risk of thyroid function deterioration over time, irrespectively of whether HT-related SH was or was not

Table 3 Prevalences (\%) of the different biochemical patterns of thyroid function detected, at the end of a 5-year follow-up, in the two groups with either idiopathic subclinical hypothyroidism (SH; group A) or Hashimoto's thyroiditis (HT)-related SH (group B) and in three subgroups of patients with HT-related SH and a percentage of those who, in the different groups and subgroups, required $\mathrm{L}-\mathrm{T}_{4}$ treatment during follow-up.

\begin{tabular}{|c|c|c|c|c|c|c|}
\hline & Euthyroidism & SH & $\begin{array}{c}\text { Overt } \\
\text { hypothyroidism }\end{array}$ & Hyperthyroidism & $\begin{array}{c}\text { Overall } \\
\text { dysfunctions }\end{array}$ & L-T 4 therapy \\
\hline Group A $(n=42)$ & 61.9 & 26.2 & 11.9 & 0 & 38.1 & 23.8 \\
\hline Group B $(n=85)$ & 10.6 & 55.3 & 30.6 & 3.5 & 89.4 & 63.5 \\
\hline$P$ & 0.0001 & 0.0020 & 0.0200 & 0.2180 & 0.0001 & 0.0001 \\
\hline Subgroup B1 $(n=22)^{a}$ & 36.4 & 18.2 & 45.4 & 0 & 63.6 & 63.6 \\
\hline Subgroup B2 $(n=21)^{\mathrm{b}}$ & 0 & 33.3 & 66.7 & 0 & 100 & 80.9 \\
\hline Subgroup B3 $(n=42)^{\mathrm{C}}$ & 2.4 & 85.7 & 4.8 & 7.1 & 97.6 & 54.8 \\
\hline$P A$ vs $B 1$ & 0.0520 & 0.4730 & 0.0030 & - & 0.0520 & 0.0020 \\
\hline$P$ B1 vs B2 & 0.0020 & 0.2550 & 0.1610 & - & 0.0020 & 0.2060 \\
\hline$P$ B1 vs B3 & 0.0002 & 0.0001 & 0.0001 & 0.1990 & 0.0002 & 0.4950 \\
\hline$P$ B2 vs B3 & 0.4760 & 0.0001 & 0.0001 & 0.2090 & 0.4760 & 0.0420 \\
\hline
\end{tabular}


associated with TS or DS. In fact, even in the subgroup with HT and no chromosomopathies, $\mathrm{L}_{-} \mathrm{T}_{4}$ therapy was needed more often than in the group with idiopathic $\mathrm{SH}$.

The different $\mathrm{SH}$ outcome in groups $\mathrm{A}$ and $\mathrm{B}$ cannot be explained by a different age or a different distribution of prepubertal and pubertal patients, because such parameters were very similar in the two groups.

Another peculiar aspect of the present study is that the patient series with HT-related $\mathrm{SH}$ was in turn divided in three subcohorts of girls with or without chromosomopathies. This study design gave us the opportunity to evaluate whether the association with either TS or DS may modify the natural history of mild SH in the girls with HT.

Our results confirm, throughout a prospective 5-year study, the sporadic reports that the association with either TS $(26,37)$ or DS $(38)$ seems to be able to affect the course of HT by increasing the risk of a thyroid function deterioration over time. In particular, it is noteworthy that the almost totality of our patients with HT-related SH and associated TS or DS exhibited, at the end of the observation period, a biochemical picture of thyroid dysfunction: either $\mathrm{SH}$, overt hypothyroidism or hyperthyroidism.

In the present study, both TGAb and TPOAb serum levels were distinctly lower in DS girls than in those with TS, which seems to support the hypothesis that, in the pathogenesis of HT-related SH, other factors apart from autoimmunity might be involved in DS patients $(39,40$, 41). However, it has to be emphasized that, in the present study, all the DS girls with SH exhibited an underlying HT.

A further finding that deserves to be emphasized in this study is that, in $7.1 \%$ of DS girls, HT switched over time toward GD. This is not surprising considering that such a conversion is known to be detectable in the natural history of patients with HT $(42,43,44,45,46)$ and has also been specifically described in children with either TS $(29,30,31)$ or DS $(38,47)$. Moreover, the shifting HT $\rightarrow$ GD has been, just recently, found to be more common in GD children with these chromosomal aberrations than in those without them (48).

Finally, from a methodological point of view, it is known that age-specific reference ranges should be used when measuring $\mathrm{TSH}$ and $\mathrm{FT}_{4}$ in children. During very early life, in fact, the values of these hormones may range widely, making it challenging to interpret measurements in infants and, especially, newborns (49). In the present study, however, median ages of the girls included in the two study groups with either idiopathic or HT-related SH were very similar and no patients $<2.5$ or $>18$ years were initially included in the overall study population.
Nevertheless, we are well aware of the fact that, in the context of group B, median ages were significantly different in the subgroups, particularly between subgroups $\mathrm{B} 2$ and B3. Therefore, TSH and $\mathrm{FT}_{4}$ values in these subgroups might be hard to compare among them. In fact, it is known that TSH values are greatest during the first months of life and subsequently tend to decrease with age (50).

Surprisingly, in the present study, the highest TSH values were detected, both at entry and at the end of followup, in the subgroup of TS patients, i.e., those with the most advanced median age. These findings suggest that, if compared with the other patient subgroups, the TS girls with HT-related SH are per se more inclined to deteriorate their thyroid status over time, irrespective of age.

\section{Conclusion}

Long-term prognosis of mild and idiopathic $\mathrm{SH}$ is frequently benign, even though a $\mathrm{L}_{-} \mathrm{T}_{4}$ treatment may be needed throughout follow-up in almost a quarter of cases. Long-term prognosis is different in the girls with either idiopathic or HT-related SH. The association with either TS or DS impairs the outcome of HT-related SH.

\section{Declaration of interest}

The authors declare that there is no conflict of interest that could be perceived as prejudicing the impartiality of the research reported.

\section{Funding}

This research did not receive any specific grant from any funding agency in the public, commercial or not-for-profit sector.

\section{References}

1 Cooper DS \& Biondi B. Subclinical thyroid disease. Lancet 2012379 1142-1154. (doi:10.1016/S0140-6736(11)60276-6)

2 Lazar L, Frumkin RB, Battat E, Lebenthal Y, Phillip M \& Meyerovitch J. Natural history of thyroid function tests over 5 years in a large pediatric cohort. Journal of Clinical Endocrinology and Metabolism 200994 1678-1682. (doi:10.1210/jc.2008-2615)

3 Zadik Z. Overuse or misuse of thyroid function tests in pediatrics. Journal of Pediatric Endocrinology \& Metabolism 200922 875-876. (doi:10.1515/JPEM.2009.22.10.875)

4 Arrigo T, Wasniewska M, Crisafulli G, Lombardo F, Messina MF, Rulli I, Salzano G, Valenzise M, Zirilli G \& De Luca F. Subclinical hypothyroidism: the state of the art. Journal of Endocrinological Investigation 200831 79-84. (doi:10.1007/BF03345571)

5 Villar HC, Saconato H, Valente O \& Atallah AN. Thyroid hormone replacement for subclinical hypothyroidism. Cochrane Database of Systematic Reviews 20073 CD003419. (doi:10.1002/14651858. CD003419.pub2) 
6 Niedziela M. Subclinical hypothyroidism: dilemmas in the treatment of children. Journal of Endocrinological Investigation 200730 529-531. (doi:10.1007/BF03346340)

7 Monzani A, Prodam F, Rapa A, Moia S, Agarla V, Bellone S \& Bona G. Endocrine disorders in childhood and adolescence. Natural history of subclinical hypothyroidism in children and adolescents and potential effects of replacement therapy: a review. European Journal of Endocrinology 2012168 R1-R11. (doi:10.1530/EJE-12-0656)

8 Bona G, Prodam F \& Monzani A. Subclinical hypothyroidism in children: natural history and when to treat. Journal of Clinical Research in Pediatric Endocrinology 20135 (Suppl 1) 23-28. (doi:10.4274/jcrpe.851)

9 De Luca F, Corica D, Pitrolo E, Santucci S \& Romeo M. Idiopathic and mild subclinical hypothyroidism in childhood: clinical management. Minerva Pediatrica 201466 63-68.

10 O'Grady MJ \& Cody D. Subclinical hypothyroidism in childhood. Archives of Disease in Childhood 201196 280-284. (doi:10.1136/adc. 2009.181800)

11 Wasniewska M, Corrias A, Aversa T, Valenzise M, Mussa A, De Martino L, Lombardo F, De Luca F \& Salerno M. Comparative evaluation of therapy with L-thyroxine versus no treatment in children with idiopathic and mild subclinical hypothyroidism. Hormone Research in Paediatrics 201277 376-381. (doi:10.1159/000339156)

12 Aversa T, Valenzise M, Corrias A, Salerno M, De Luca F, Mussa A, Rezzuto M, Lombardo F \& Wasniewska M. Underlying Hashimoto's thyroiditis negatively affects the evolution of subclinical hypothyroidism in children irrespective of other concomitant risk factors. Thyroid 201525 183-187. (doi:10.1089/thy.2014.0235)

13 Wasniewska M, Salerno M, Cassio A, Corrias A, Aversa T, Zirilli G, Capalbo D, Bal M, Mussa A \& De Luca F. Prospective evaluation of the natural course of idiopathic subclinical hypothyroidism in childhood and adolescence. European Journal of Endocrinology 2009160 417-421. (doi:10.1530/EJE-08-0625)

14 De Luca F, Wasniewska M, Zirilli G, Aversa T \& Arrigo T. At the end of a two-year follow-up elevated TSH levels normalize or remain unchanged in most the children with subclinical hypothyroidism. Italian Journal of Pediatrics 201036 11. (doi:10.1186/1824-7288-36-11)

15 Cerbone M, Bravaccio C, Capalbo D, Polizzi M, Wasniewska M, Cioffi D, Improda N, Valenzise M, Bruzzese D, De Luca F et al. Linear growth and intellectual outcome in children with long-term idiopathic subclinical hypothyroidism. European Journal of Endocrinology 2011164 591-597. (doi:10.1530/EJE-10-0979)

16 Radetti G, Maselli M, Buzi F, Corrias A, Mussa A, Cambiaso P, Salerno M, Cappa M, Baiocchi M, Gastaldi R et al. The natural history of the normal/mild elevated TSH serum levels in children and adolescents with Hashimoto's thyroiditis and isolated hyperthyrotropinaemia: a 3-year follow-up. Clinical Endocrinology 201276 394-398. (doi:10.1111/ j.1365-2265.2011.04251.x)

17 Elsheikh M, Dunger DB, Conway GS \& Wass JA. Turner's syndrome in adulthood. Endocrine Reviews 200223 120-140. (doi:10.1210/edrv.23.1.0457)

18 Roizen NJ \& Patterson D. Down's syndrome. Lancet 2003361 1281-1289. (doi:10.1016/S0140-6736(03)12987-X)

19 Goldacre MJ, Wotton CJ, Seagroatt V \& Yeates D. Cancers and immune related diseases associated with Down's syndrome: a record linkage study. Archives of Disease in Childhood 200489 1014-1017. (doi:10.1136/adc.2003.046219)

20 Bakalov VK, Gutin L, Cheng CM, Zhou J, Sheth P, Shah K, Arepalli S, Vanderhoof V, Nelson LM \& Bondy CA. Autoimmune disorders in women with Turner syndrome and women with karyotypically normal primary ovarian insufficiency. Journal of Autoimmunity 201238 315-321. (doi:10.1016/j.jaut.2012.01.015)

21 Larizza D, Calcaterra V \& Martinetti M. Autoimmune stigmata in Turner syndrome: when lacks an X chromosome. Journal of Autoimmunity 200933 25-30. (doi:10.1016/j.jaut.2009.03.002)

22 Jørgensen KT, Rostgaard K, Bache I, Biggar RJ, Nielsen NM, Tommerup N \& Frisch M. Autoimmune diseases in women with
Turner's syndrome. Arthritis and Rheumatism 201062 658-666. (doi:10.1002/art.27270)

23 Salzano G, Lombardo F, Arrigo T, Sferlazzas C, Wasniewska M, Valenzise $\mathrm{M} \&$ De Luca F. Association of five autoimmune diseases in a young woman with Down's syndrome. Journal of Endocrinological Investigation 201033 202-203. (doi:10.1007/BF03346582)

24 Lleo A, Moroni L, Caliari L \& Invernizzi P. Autoimmunity and Turner's syndrome. Autoimmunity Reviews 201211 A538-A543. (doi:10.1016/ j.autrev.2011.11.015)

25 Grossi A, Crinò A, Luciano R, Lombardo A, Cappa M \& Fierabracci A. Endocrine autoimmunity in Turner syndrome. Italian Journal of Pediatrics 201339 79. (doi:10.1186/1824-7288-39-79)

26 Livadas S, Xekouki P, Fouka F, Kanaka-Gantenbein C, Kaloumenou I, Mavrou A, Constantinidou N \& Dacou-Voutetakis C. Prevalence of thyroid dysfunction in Turner's syndrome: a long-term follow-up study and brief literature review. Thyroid 200515 1061-1066. (doi:10.1089/ thy.2005.15.1061)

27 Fukuda I, Hizuka N, Kurimoto M, Morita J, Tanaka S, Yamakado Y \& Takano K. Autoimmune thyroid diseases in 65 Japanese women with Turner syndrome. Endocrine Journal 200956 983-986. (doi:10.1507/ endocrj.K09E-141)

28 Goday-Arno A, Cerda-Esteva M, Flores-Le-Roux JA, Chillaron-Jordan JJ, Corretger JM \& Cano-Pérez JF. Hyperthyroidism in a population with Down syndrome (DS). Clinical Endocrinology 200971 110-114. (doi:10.1111/j.1365-2265.2008.03419.x)

29 Wasniewska M, Corrias A, Messina MF, Crisafulli G, Salzano G, Valenzise M, Mussa A \& De Luca F. Graves' disease prevalence in a young population with Turner syndrome. Journal of Endocrinological Investigation 201033 69-70. (doi:10.1007/BF03346552)

30 Gawlik A, Gawlik T, Januszek-Trzciakowska A, Patel H \& MaleckaTendera E. Incidence and dynamics of thyroid dysfunction and thyroid autoimmunity in girls with Turner's syndrome: a long-term follow-up study. Hormone Research in Paediatrics 201176 314-320. (doi:10.1159/ 000331050)

31 Valenzise M, Aversa T, Corrias A, Mazzanti L, Cappa M, Ubertini G, Scarano E, Mussa A, Messina MF, De Luca F et al. Epidemiology, presentation and long-term evolution of Graves' disease in children, adolescents and young adults with Turner syndrome. Hormone Research in Paediatrics 201481 245-250. (doi:10.1159/000357130)

32 Cooper DS. Clinical practice. Subclinical hypothyroidism. New England Journal of Medicine 2001345 260-265. (doi:10.1056/ NEJM200107263450406)

33 Lazarus J, Brown RS, Daumerie C, Hubalewska-Dydejczyk A, Negro R \& Vaidya B. European Thyroid Association guidelines for the management of subclinical hypothyroidism in pregnancy and in children. European Thyroid Journal 20143 76-94. (doi:10.1159/000362597)

34 Wasniewska M, Corrias A, Salerno M, Mussa A, Capalbo D, Messina MF, Aversa T, Bombaci S, De Luca F \& Valenzise M. Thyroid function patterns at Hashimoto's thyroiditis presentation in childhood and adolescence are mainly conditioned by patients' age. Hormone Research in Paediatrics 201278 232-236. (doi:10.1159/000343815)

35 Wasniewska M, Corrias A, Salerno M, Lombardo F, Aversa T, Mussa A, Capalbo D, De Luca F \& Valenzise M. Outcomes of children with hashitoxicosis. Hormone Research in Paediatrics 201277 36-40. (doi:10.1159/000334640)

36 Gawlik A, Such K, Dejner A, Zachurzok A, Antosz A \& MaleckaTendera E. Subclinical hypothyroidism in children and adolescents: is it clinically relevant? International Journal of Endocrinology 20152015 691071. (doi:10.1155/2015/691071)

37 Aversa T, Messina MF, Mazzanti L, Salerno M, Mussa A, Faienza MF, Scarano E, De Luca F \& Wasniewska M. The association with Turner syndrome significantly affects the course of Hashimoto's thyroiditis in children, irrespective of karyotype. Endocrine 2015. In press. (doi:10.1159/000357130)

38 Aversa T, Salerno M, Radetti G, Faienza MF, Iughetti L, Corrias A, Predieri B, Mussa A, Mirabelli M, De Luca F et al. Peculiarities of 
presentation and evolution over time of Hashimoto's thyroiditis in children and adolescents with Down's syndrome. Hormones 201514 410-416. (doi:10.14310/horm.2002.1574)

39 van Trotsenburg AS, Vulsma T, van Rozenburg-Marres SL, van Baar AL, Ridder JC, Heymans HS, Tijssen JG \& de Vijlder JJ. The effect of thyroxine treatment started in the neonatal period on development and growth of two-year-old Down syndrome children: a randomized clinical trial. Journal of Clinical Endocrinology and Metabolism 200590 3304-3311. (doi:10.1210/jc.2005-0130)

40 Meyerovitch J, Antebi F, Greenberg-Dotan S, Bar-Tal O \& Hochberg Z. Hyperthyrotropinaemia in untreated subjects with Down's syndrome aged 6 months to 64 years: a comparative analysis. Archives of Disease in Childhood 201297 595-598. (doi:10.1136/archdischild-2011300806)

41 Claret C, Goday A, Benaiges D, Chillarón JJ, Flores JA, Hernandez E, Corretger JM \& Cano JF. Subclinical hypothyroidism in the first years of life in patients with Down syndrome. Pediatric Research 201373 674-678. (doi:10.1038/pr.2013.26)

42 Ludgate M \& Emerson $\mathrm{CH}$. Metamorphic thyroid autoimmunity. Thyroid 200818 1035-1037. (doi:10.1089/thy.2008.1551)

43 Wasniewska M, Corrias A, Arrigo T, Lombardo F, Salerno M, Mussa A, Vigone MC \& De Luca F. Frequency of Hashimoto's thyroiditis antecedents in the history of children and adolescents with Graves' disease. Hormone Research in Paediatrics 201073 473-476. (doi:10.1159/ 000313395)

44 Kamath C, Young S, Kabelis K, Sanders J, Adlan MA, Furmaniak J, Rees Smith B \& Premawardhana LD. Thyrotrophin receptor antibody characteristics in a woman with long-standing Hashimoto's who developed Graves' disease and pretibial myxoedema. Clinical Endocrinology 201277 465-470. (doi:10.1111/j.1365-2265.2012.04397.x)

45 Troisi A, Novati P, Sali L, Colzani M, Monti G, Cardillo C \& Tesauro M. Graves' thyrotoxicosis following Hashimoto's thyroiditis. Research and Reports in Endocrine Disorders 20133 13-15. (doi:10.2147/RRED.S38053)

46 Champion B, Gopinath B, Ma G, El-Kaissi S \& Wall JR. Conversion to Graves' hyperthyroidism in a patient with hypothyroidism due to Hashimoto's thyroiditis documented by real-time thyroid ultrasonography. Thyroid 200818 1135-1137. (doi:10.1089/thy.2008.0142)

47 De Luca F, Corrias A, Salerno M, Wasniewska M, Gastaldi R, Cassio A, Mussa A, Aversa T, Radetti G \& Arrigo T. Peculiarities of Graves' disease in children and adolescents with Down's syndrome. European Journal of Endocrinology 2010162 591-595. (doi:10.1530/EJE-09-0751)

48 Aversa T, Lombardo F, Corrias A, Salerno M, De Luca F \& Wasniewska M. In young patients with Turner or Down syndrome, Graves' disease presentation is often preceded by Hashimoto's thyroiditis. Thyroid 201424 744-747. (doi:10.1089/thy.2013.0452)

49 Verburg FA, Kirchgässner C, Hebestreit H, Steigerwald U, Lentjes EG, Ergezinger K, Grelle I, Reiners C \& Luster M. Reference ranges for analytes of thyroid function in children. Hormone and Metabolic Research 201143 422-426. (doi:10.1055/s-0031-1275326)

50 Kapelari K, Kirchlechner C, Högler W, Schweitzer K, Virgolini I \& Moncayo R. Pediatric reference intervals for thyroid hormone levels from birth to adulthood: a retrospective study. BMC Endocrine Disorders 20088 15. (doi:10.1186/1472-6823-8-15)

Received 11 May 2015

Revised version received 27 July 2015

Accepted 15 September 2015 